(2) Open Access Full Text Article

REVIEW

\title{
Language and emotional abilities in children with Williams syndrome and children with autism spectrum disorder: similarities and differences
}

This article was published in the following Dove Press journal:

Pediatric Health, Medicine and Therapeutics

22 July 2016

Number of times this article has been viewed

\begin{abstract}
Agnès Lacroix'
Nawelle Famelart ${ }^{2}$

Michèle Guidetti ${ }^{2}$

'Department of Psychology, Center for Research in Psychology, Cognition, and Communication, University of Rennes 2, Rennes, ${ }^{2}$ CLLE, Université de Toulouse, CNRS, UT2], France
\end{abstract}

\begin{abstract}
Williams syndrome (WS) is a genetic disease with a relatively homogeneous profile: relatively well-preserved language, impaired cognitive activities, and hypersociability. Autism spectrum disorder (ASD) refers to a group of individuals with impairments in aspects of communication and a particular pattern of language acquisition. Although ASD and WS are polar opposites when it comes to communication abilities (language and emotion) and social behavior, comparisons between WS and ASD are still rare in the literature. ASD and WS are both associated with general language and developmental delays. Difficulties in social interaction and general pragmatic difficulties are reported in both ASD and WS, but are more pervasive in ASD. Regarding facial emotion recognition, the two syndromes differ markedly in sensitivity to human faces. Despite the heterogeneity of these two groups, only a few studies with children have paid sufficient attention to participant recruitment and study design. A number of aspects need to be taken into account (eg, small age range, homogeneity of the subgroups, matching with typically developing children) if scientific results are to inform the design of intervention programs for children with neurodevelopmental disorders such as ASD and WS.
\end{abstract}

Keywords: neurodevelopmental disorders, facial emotion recognition, linguistic abilities, pragmatic abilities, emotions

\section{Introduction}

Language and emotion are both processes whose main function is communication. They allow individuals to communicate about the nature of their intentions and their motivations, and thus, to regulate interpersonal relations. Their successful development and acquisition allow individuals to adopt appropriate behaviors in the society, and are intertwined with the emergence of certain cognitive abilities. Nevertheless, emotion is a complex and multifarious domain. It involves the production and comprehension of perceptual aspects, as well as linguistic ones. The comparison between Williams syndrome (WS) and autism spectrum disorder (ASD) regarding emotions is heuristic, in the sense that these two neurodevelopmental disorders can be viewed as polar opposites in terms of sociability. Both have nonuniform cognitive profiles. Their comparison is, therefore, of both theoretical and applied (assessment and care) interest. People with WS are socially engaged and interested in others, even unfamiliar persons, and are particularly attracted to human faces, whereas individuals with ASD exhibit deficits in social interaction and prefer inanimate objects to human faces. The aim of the present paper is to highlight the similarities and differences in language and emotional abilities between WS and ASD. After giving a general description of emotional abilities and language in these two disorders, we focus on the studies that have compared WS and ASD.
Correspondence: Agnès Lacroix Department of Psychology, Center for Research in Psychology, Cognition, and Communication, Université Européenne de Bretagne - Rennes 2, CRPCC, Place du Recteur Henri Le Moal, 35043 Rennes Cedex, France

Tel +33299141900

Email agnes.lacroix@uhb.fr
Pediatric Health, Medicine and Therapeutics 2016:7 89-97

Dovepress

http://dx.doi.org/1 0.2147/PHMT.S66347 (c) (1) 2016 Lacroix et al. This work is published and licensed by Dove Medical Press Limited. The full terms of this license are available at https://www.doress. cc) 2 By and incorporate the Creative Commons Attribution - Non Commercial (unported, v3.0) License (http://creativecommons.org/licenses/by-nc/3.0/). By accessing the work you hereby accept the Terms. Non-commercial uses of the work are permitted without any further permission from Dove Medical Press Limited, provided the work is properly attributed. For

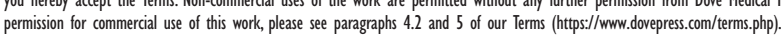




\section{Williams syndrome}

WS is a rare genetic disease ( 1 in 20,000 births) caused by a microdeletion on chromosome 7 (7q11.23). ${ }^{1-3}$ Persons with WS are characterized by a heart condition and a facial dysmorphology described as elfin. From the intellectual standpoint, individuals with WS usually have an intelligence quotient of between 50 and 70 . Their unique neuropsychological profile has often been described as dissociation between cognition and language. Language is relatively well preserved, whereas cognition (ie, visuospatial abilities, executive functions, and number skills) is impaired. ${ }^{4-6}$ Moreover, individuals with WS are characterized by hypersociability because of their ease in interacting with unfamiliar people. ${ }^{7,8}$

Regarding morphosyntax, problem areas include "grammatical gender", which could be explained by the interaction of multiple factors, including attention deficit. ${ }^{9} 10$ Moreover, for conjugations and plurals, there is a dissociation between regular and irregular forms, in favor of regular ones. ${ }^{11-18}$ Some recent studies have shown that while the development of morphosyntactic aspects is similar to that observed in typical development, there is a 1-year lag. ${ }^{19-21}$ Researchers claim that mental retardation cannot entirely explain the poor morphosyntactic abilities that individuals with WS display in narrative tasks. ${ }^{22,23}$ Concerning syntactic abilities, some authors ${ }^{14,24,25}$ showed that children with WS perform well, but their syntactic abilities vary according to the context. ${ }^{19,26}$ Meanwhile, Volterra et $\mathrm{al}^{27}$ highlighted a delay in acquisition, suggesting that the ability to listen to and store the sounds of words is intact in WS. This ability would allow them to acquire some of the more difficult aspects of language. For their part, Losh et $\mathrm{a}^{22}$ and Reilly et $\mathrm{al}^{23}$ observed that children with WS use a less complex syntax than typical children. Grant et a ${ }^{28}$ recorded the same results in a repetition task.

In the lexical domain, Bellugi et $\mathrm{al}^{24,25,29}$ and Bromberg et al ${ }^{30,31}$ described their semantics as unusual (use of rare words). The lexicon of adolescents and adults with WS is similar in quantity and diversity to that of typical individuals..$^{24,25,32}$ In 1997, Stevens and Karmiloff-Smith ${ }^{33}$ showed that children with WS can achieve good lexical levels, even if they do not master all the lexical constraints. Tyler et al ${ }^{34}$ highlighted several lexical-semantic deficits in WS, characterized by difficulty defining frequently used words and difficulty with lexical access. Moreover, Johnson and Carey ${ }^{35}$ and Jarrold et $\mathrm{al}^{36}$ showed that individuals with WS are able to enrich their semantic knowledge. For their part, Lukács et al ${ }^{15,16}$ and Temple et $\mathrm{al}^{37}$ found that the profile of access to semantic networks is characterized by representations that are looser or only partially activated for naming and pointing. In 2003,
Levy and Balchar ${ }^{38}$ showed that in semantic and phonological fluency tasks, children with WS and their typical peers produce similar numbers of words. Nevertheless, Levy ${ }^{14}$ found that the former produce more errors. Nazzi and KarmiloffSmith ${ }^{39}$ showed that children with WS do not attend to the role played by nouns in the formation of categories, observing dissociation between lexical acquisition and the development of name-based categorization.

The few studies that have examined the pragmatic aspects of language in individuals with WS have focused on communicative, narrative, or conversational skills. ${ }^{2}$ Based on the Vineland Adaptive Behavior Scales, ${ }^{40}$ Mervis et al ${ }^{41}$ ranked the abilities of children with WS as follows: socialization (strongest point), communication, daily living skills, and motor abilities (weakest point). These abilities were found to improve with age. In Laws and Bishop's study, ${ }^{42}$ parents, teachers, and other professionals were asked to fill out the Children's Communication Checklist for WS. Results indicated that the WS group had a pragmatic deficit marked by inappropriate initiation of interactions and stereotyped conversations. Jones et $\mathrm{al}^{43,44}$ claimed that inappropriate initiation is due to a lack of inhibition with respect to unknown persons. Mervis et $\mathrm{a}^{41}$ and Laws and Bishop ${ }^{42}$ further highlighted the disparity between the relatively good ability to socialize and the difficulty of interacting appropriately with others. Lacroix et al, ${ }^{2}$ Losh et al, ${ }^{22}$ and Reilly et a ${ }^{45}$ looked at social evaluation, which involves assessing the speaker's subjective point of view with respect to the listener and the story. Children with WS were found to engage more in social evaluation (dialogues between characters and attributing affective states) than their typical peers. These results were replicated by Reilly et al. ${ }^{46}$ Lacroix et $\mathrm{al}^{2}$ showed that children and adolescents with WS have a unique profile of pragmatic abilities, accounting for the nonhomogeneity of narrative skills in WS (ie, a deficit in narrative structuring and excessive engagement in social evaluation, compatible with the hypersociability described in WS). Stojanovik et al ${ }^{47}$ and Stojanovik ${ }^{48}$ found that some of the utterances produced by children were inappropriate, featuring semantic and syntactic problems. Despite their reputation for being highly talkative, they actually supplied very little information. Regarding turn-taking violations, there was no difference between the groups. Nevertheless, the replies given by the children with WS to adults' requests were not well adapted. Thus, it seems that children with WS have relatively poor conversational skills.

People with WS are described as sociable, friendly, and empathic, and they exhibit considerable sociability, such as 
engaging with unfamiliar people. This positive social bias is thought to affect their perception of facial expressions of emotions, leading to more positive interpretations of them. ${ }^{49}$ Some studies on the identification of emotions ${ }^{50-52}$ have indicated that children with WS perform similarly to typical children. However, Jones et a ${ }^{43,44}$ and Plesa-Skewer et $\mathrm{al}^{53}$ found that whereas a WS group performed just as well as typical controls on happiness, children of the WS group performed less well on negative emotions. The same results were observed for the revised Reading the Mind in the Eyes Task. ${ }^{54}$ Facial emotion recognition is, therefore, not a spared ability in WS, unlike facial identity recognition. When Porter et $\mathrm{a}^{55}$ studied the recognition of facial expressions of emotion in individuals with WS, they found that negative emotions were often identified as positive. The authors attributed this result to the positive social bias arising from a sociable personality-Doyle et $\mathrm{al}^{7}$ had previously shown that children with WS are judged to be more sociable than typical children. In the Benton Facial Recognition Test,$^{56}$ children with WS have no difficulty matching two identical faces expressing distinct emotions..$^{24,25,50,52}$ By contrast, several studies have highlighted a developmental lag in facial recognition in WS. ${ }^{51,57}$ Moreover, researchers have suggested that face processing is abnormal in WS, owing to the use of a local process rather than a global one. More specifically, Tager-Flusberg et a ${ }^{58}$ showed that persons with WS have an advantage when it comes to processing complete faces when they are normally oriented, but not when they are inverted.

Regarding emotion production abilities, Jones et $\mathrm{al}^{43,44}$ found that children with WS less frequently produced negative facial expressions. Moreover, their expressions of vocal and facial distress and negativity were less intense than those of typical controls. When they were reunited with their parents, the frequency and intensity of their positive expressions were the same as those in the two control groups. Furthermore, when children with WS were shown a toy behind a barrier in a warm-up task, they tended to excessively engage the examiner through eye contact and smiling, compared with typically developing children. Regarding emotion regulation abilities, Phillips ${ }^{59}$ carried out a study including 37 children and adolescents with WS, who were aged $8-15$ years. Results indicated that most of these participants had difficulty regulating their emotions. Moreover, the author showed that their emotion regulation difficulties were correlated with measures of adaptive behavior. The high level of emotion regulation difficulties was more likely to be interpreted by their parents as internalizing and externalizing behavior problems.

\section{Autism spectrum disorder}

ASD refers to a group of neurodevelopmental disorders marked by impairments in social interaction and communication, and repetitive and stereotypical behavior, which are generally evident before 3 years of age, according to the Diagnostic and Statistical Manual of Mental Disorders, Fifth Edition. ${ }^{60}$ Although impairments in aspects of communication are considered to be one of the core deficits in ASD, less is known about the structural aspects of language acquisition in ASD. ${ }^{61-66}$ Because of this disorder's variability of expression, there is also considerable variation in language skills among individuals with ASD. Impaired language use is one of the earliest symptoms that alerts parents to their children's development. ${ }^{65,67}$ Moreover, ASD is classically characterized by impairments in the processing of social and emotional information, responses to the emotional displays of others, and face recognition ${ }^{49}$ In ASD, several language impairments have been described, such as developmental delay, echolalia, and pragmatic difficulties.

Individuals with ASD display deficits in communication, pragmatics, and social aspects of language.$^{62}$ However, the same is not true for grammar. It has been argued that lower functioning individuals are more at risk of deficient grammar than higher functioning individuals so much so that "language impairment and intellectual disability almost always occur together when associated with autism" ${ }^{61}$ In children with Asperger syndrome, grammar has been reported to be mostly spared. ${ }^{61}$ Following Tager-Flusberg et al ${ }^{65}$ it is now common in the literature to identify two major subgroups within the ASD population: children with ASD whose performances on standardized language assessments are in the impaired range and children with ASD whose language seems normal on standardized measures.

Studies on morphology in children with ASD are rare. Nevertheless, some research has demonstrated that grammar is relatively intact. In a longitudinal study of six children with ASD aged 3-7 years, Tager-Flusberg et a ${ }^{166}$ observed that they followed the same developmental pattern as typical children, in terms of increases in the mean length of utterance. For their part, Naigles et al ${ }^{68}$ demonstrated that preschoolers with ASD have levels comparable to those of language-matched typically developing children, when it comes to understanding some syntactic-semantic linkages. Other studies, however, have reported atypical morphosyntax in children with ASD. Bartolucci et $\mathrm{a}^{69}$ found that children with ASD were more likely than children in other groups to omit certain morphemes (articles, auxiliary forms, past tense). They also found that these morphemes emerged later in the speech of 
children with ASD. This finding was replicated by Howlin. ${ }^{70}$ More recently, Eigsti et al ${ }^{62}$ investigated spontaneous speech during free play in 3- to 6-year-old children with ASD. These authors found that the children with ASD produced few syntactically complex utterances - a finding confirmed by Park et al. ${ }^{64}$ In ASD, morphology is acknowledged to be deficient, especially finiteness marking. ${ }^{71,72}$

The few experimental studies that have investigated complex syntactic structures have highlighted difficulty with passives, ${ }^{73,74}$ relative clauses,${ }^{75}$ raising,${ }^{73}$ and subject control structures.

Some studies, however, have reported intact lexical/ semantic skills in ASD. Vocabularies increase steadily with age, but are composed primarily of nouns. ${ }^{66,76,77}$ Even though young children with ASD may not rely on the same lexical learning mechanisms as typical children, they can still acquire a sizable vocabulary. ${ }^{78-80}$ Mental state terms have also been shown to be underrepresented in conversations, suggesting that vocabulary use by children with ASD may be deficient, compared with that of typical children. ${ }^{81}$

Pragmatic skills are generally considered to be impaired in ASD. Rutter et $\mathrm{al}^{82}$ found that children with ASD tend to use formal words, suggesting a lack of experience with peer interactions and a preference for interacting with adults. Volden $^{83}$ showed that they are able to respond to failures of communication, but produce inappropriate responses. This last finding is consistent with earlier ones. ${ }^{84}$ In narrative situations, children with ASD have difficulty understanding why a character feels a particular internal state. ${ }^{85}$

Interpreting the results of studies in ASD is a complex business, as it depends on the methodology and the homogeneity of the sample. As mentioned by Lacroix et al, ${ }^{49}$ ASD is often characterized by deficits in the processing of social and emotional information, ${ }^{86-88}$ responses to the emotional displays of others, ${ }^{89}$ and face recognition. ${ }^{90-92}$ More specifically, children with ASD perform better for simple emotions related to external situations (happiness and sadness) than for emotions related to internal cognition, such as surprise, ${ }^{93-95}$ and they are less sensitive to negative emotions. ${ }^{89}$ People with ASD have difficulty recognizing, identifying, and understanding the significance of emotions. ${ }^{96-98}$ Recently, Castelli ${ }^{99}$ claimed that children with ASD are just as capable of identifying emotions from facial expressions as typically developing children. By contrast, Lindner and Rosen ${ }^{100}$ reported that children with Asperger syndrome find it harder than typically developing children to identify emotions in static facial expressions, dynamic facial expressions, and tones of voice. Losh et $\mathrm{al}^{63}$ showed that high-functioning people with autism, aged between 16 and 27 years, had difficulties to identify fear, but not with happiness and sadness. More recently, Lacroix et al $^{101}$ showed that children with ASD, aged 4-8 years, had greater difficulty labeling emotions, though not with matching or identifying them, than typically developing children matched on either chronological or verbal mental age. Happiness was the easiest one to recognize, and surprise the hardest. The children with ASD did not exhibit any delayed onset in the development of facial emotion recognition. Emotion recognition difficulties in children with ASD, therefore, are primarily concerned with the recognition of negative emotions and the identification of surprise, just as they do in typically developing groups.

\section{Comparisons between WS and ASD}

Few studies have compared the two developmental disorders, and we only found one study for language abilities. Philofsky et $\mathrm{al}^{102}$ investigated the pragmatic language profiles of children with ASD and children with WS. They administered the Children's Communication Checklist- $2^{103}$ to 22 parents of children with ASD aged between 7 years and 1 month, and 12 years and 10 months, 21 parents of children with WS aged between 6 years and 2 months, and 12 years and 5 months, and 19 parents of typically developing children aged between 5 years and 10 months, and 10 years. Results indicated similar levels of pragmatic impairment in the ASD and WS groups, especially for the Inappropriate Initiation, Use of Context, and Interests scales. However, the children with WS performed significantly better than those with ASD on the Coherence, Stereotyped Language, Nonverbal Communication, and Social Relations scales. The children with WS had several areas of relative strength, compared with the children with ASD, who exhibited impaired social pragmatic functioning. The children with WS were given significantly higher ratings by their parents than the children with ASD on several items referring to the use and understanding of affective expressions, empathy, and social relationships. Smaller, but still significant, differences were noted in favor of the children with WS (over ASD), regarding their ability to appropriately sequence and reference events for a listener. Both clinical groups displayed impairment in the quality of their initiations with others and in the overall quality and variety of their interests.

This kind of study has implications for speech-language pathologists, educators, and other professionals working with children who have these disorders. The investigation of pragmatic functioning in both groups allows for a richer understanding of what constitutes atypical pragmatic language functioning in children.

Studies of emotions comparing WS and ASD are more frequent, but still few and far between. Rose et al ${ }^{104}$ investigated 
the facial discrimination abilities of 19 participants with WS and 16 with ASD in neutral versus affective expression and upright versus inverted face conditions. Participants with WS performed at the same level as both the ASD and typical groups in the recognition of upright faces with neutral expressions. However, although the participants with WS and those with ASD both used a featural strategy to process the faces, their performances differed in the inverted neutral condition. Individuals with WS and ASD may not, therefore, process faces in an identical manner. Moreover, data revealed a strong inversion effect in the WS group relative to both the ASD and typical control groups, suggesting that individuals with WS process faces holistically, even though studies have frequently reported a local bias in visual processing. The WS group performed better than the ASD group when the emotional expression varied between stimulus and target.

Riby and Hancock ${ }^{105}$ used eyetracking techniques to investigate how individuals with ASD and WS view scenes containing people. Participants were 18 young individuals with WS, aged between 8 years 9 months, and 28 years, and 20 young individuals with ASD, aged between 6 years and 4 months, and 18 years 4 months. They were shown 20 photographs, and the authors explored their gaze behavior. Results indicated that the two groups differed both from each other and from the typically developing controls. Participants with ASD and WS were found to have a number of atypical features, but a different set for each disorder. Those with WS fixated the face, especially the eyes, for a long time, but this was not the case for those with ASD. This difference indicates that people with WS are better able to interpret gaze cues and expressions than those with ASD. In WS, the cause of hypersociability is still subject to debate. Results of Porter et $\mathrm{al}^{55}$ support the explanation whereby behavior is poorly controlled owing to frontal lobe anomalies, while Riby and Hancock ${ }^{105}$ aver that individuals with WS display prolonged eye contact because of an inability to direct their gaze appropriately or difficulty understanding social rules. Both ASD and WS are associated with atypicalities of the social brain. ${ }^{106}$ Moreover, Riby et $\mathrm{l}^{105}$ reported that individuals with ASD present deficits when they need to use the eye region, whereas people with WS perform better when they use the eye rather than the mouth region.

In 2009, Lacroix et $\mathrm{al}^{49}$ compared the two disorders on the ability to recognize emotional and nonemotional facial expressions. Participants with WS were aged between 6 years 1 month, and 15 years, and participants with ASD were aged between 4 years 9 months, and 8 years. Results failed to indicate any difference among WS, ASD, and typically developing groups, matched on verbal mental age, in performances on matching and labeling tasks. Poorer performances were, however, observed in the WS group on the identification task. Moreover, language partially facilitated the recognition of emotion, depending on the nature of the emotion. In 2009, Annaz et al ${ }^{107}$ conducted a cross-syndrome study investigating the development of holistic face recognition between ages 5 and 12 years in typically developing children $(n=25)$ and in three disorders: ASD $(n=33)$, Down syndrome $(n=15)$, and WS $(n=15)$. A target face was displayed on a screen, above two stimuli: either whole faces (whole-face discrimination) or isolated facial features (part-face discrimination). Participants had to say which stimulus was the same as the target face. People with WS and ASD performed better on the part-face discrimination task than on the whole-face one. More specifically, the participants with WS seemed to process faces at the level of facial features such as the nose, mouth, and eyes, whereas participants with ASD, and more specifically high-functioning autism, relied on more finegrained visual details.

\section{Conclusion}

ASD and WS are polar opposites when it comes to communication abilities (language and emotion) and social behavior. This is why it is interesting to compare these two neurodevelopmental disorders, although such comparisons are still rare in the literature. Concerning language abilities, language delay and poor intellectual abilities do not seem to play a major role in the grammatical development of either of the populations we investigated here, even though both ASD and WS are associated with general language and developmental lags. Difficulties with social interaction and general pragmatic difficulties are reported in both ASD and WS, but are more pervasive in ASD. These difficulties can be explained by a lack of inhibition in WS, but not in ASD. The deficits in social abilities observed in ASD and WS do not have the same origins or the same consequences. Using facial emotion recognition tasks, several studies ${ }^{104,108}$ have highlighted the contrasting social features of the two syndromes: individuals with WS are reported to have better social skills than individuals with ASD. However, Lacroix et $\mathrm{al}^{49}$ showed that children with WS have greater difficulty identifying emotions such as fear and sadness than children with ASD or typically developing children matched for verbal mental age. This could have something to do with their indiscriminate approach to strangers, relative absence of social anxiety, and poor ability to recognize facial expressions of emotion. ${ }^{109}$ The deficits observed in ASD for facial emotion recognition must be linked to their poor visual strategies and their lexical and pragmatic language difficulties. We did not find any reports of severe 
lexical or semantic deficits among participants with ASD, except regarding emotional vocabulary. We did, however, find pragmatic impairments. The deficits observed in ASD in the recognition of facial emotions, especially when language is involved in the task, could be due to the fact that people with ASD do not understand the meaning of emotions. Moreover, they have a specific way of exploring the scene and the faces to extract the meaning of the situation. The social difficulties observed in WS stem from other deficits, namely visuospatial deficits, because these children focus their attention primarily on the eyes. Furthermore, their lack of inhibition leads them to exhibit a positive social bias, preferring positive emotions to negative ones.

Given the heterogeneity of these two groups of children, and the need to find out more about their language and emotional abilities, we still lack studies that pay sufficient attention to participant recruitment (ie, small age range, homogeneity of the subgroups, matching with typically developing children, etc) and study design. Language and emotion are both complex abilities, as we have seen, and studies are often not comparable because of the different methodologies they use (stimuli, procedures, etc). Language can refer to morphology, syntax, pragmatics, and so on, while facial expression of emotions can refer to identifying, labeling, or matching, and may or may not involve language. Other aspects of emotion can refer to regulation and, more broadly, to theory of mind. Further studies will need to take all these aspects into account if we want scientific results to inform the design and assessment of intervention programs for children with ASD, WS, and other neurodevelopmental disorders. Leyfer et $\mathrm{a}^{110}$ demonstrated that $7 \%$ of children with WS meet the Diagnostic and Statistical Manual of Mental Disorders (DSM-V) criteria for ASD. Nevertheless, the particularities behind criteria such as social/communicative impairment are clearly different. It is important to specify the profile of children with WS and ASD as precisely as possible. A better understanding of the characteristics of emotional and language abilities would be useful for developing the right intervention tools.

\section{Disclosure}

The authors report no conflicts of interest in this work.

\section{References}

1. Bellugi U, Lichtenberger L, Jones W, Lai Z, St George M. The neurocognitive profile of Williams' syndrome: A complex pattern of strengths and weaknesses. In: Bellugi U, St George M, editors. Linking cognitive neuroscience and molecular genetics: New perspectives from Williams syndrome [Special Issue]. J Cognitive Neurosci. 2000;12(1):1-29.
2. Lacroix A, Bernicot J, Reilly J. Narration and collaborative conversation in French-speaking children with Williams syndrome. J Neurolinguistics. 2007;20(6):445-461.

3. Siegmüller J, Bartke S. Williams syndrome from a clinical perspective. In Bartke S, Siegmüller J, editors. Williams Syndrome Across Languages. Amsterdam: John Benjamins; 2004:9-37.

4. Karmiloff-Smith A, Thomas M, Annaz D, et al. Exploring the Williams syndrome face processing debate: the importance of building developmental trajectories. J Child Psychol Psychiatry. 2004;45(7):1258-1274.

5. Klein BP, Mervis CB. Contrasting patterns of cognitive abilities of 9- and 10-year-olds with Williams syndrome or Down syndrome. Dev Neuropsychol. 1999;16(2):177-196.

6. Pezzini G, Vicari S, Volterra V, Milani L, Ossella MT. Children with Williams's syndrome: Is there a single neuropsychological profile? Dev Neuropsychol. 1999;15:141-155.

7. Doyle TF, Bellugi U, Korenberg JR, Graham J. "Everybody in the world is my friend" hypersociability in young children with Williams' syndrome. Am J Med Genet A. 2003;124:253-263.

8. Frigerio E, Burt DM, Gagliardi C, et al. Is everybody always my friend? Perception of approachability in Williams syndrome. Neuropsychologia. 2006;44(2):254-259.

9. Karmiloff-Smith A, Grant J, Berthoud I, Davies M, Howlin P, Udwin O. Language and Williams syndrome: How intact is "intact"? Child Dev. 1997;68:246-262.

10. Monnery S, Seigneuric A, Zagar D, Robichon F. A linguistic dissociation in Williams syndrome: good at gender agreement but poor at lexical retrieval. Read Writ. 2002;15:589-612.

11. Clahsen H, Ring M, Temple C. Lexical and morphological skills in English-speaking children with Williams' syndrome. In: Bartke S, Siegmüller J, editors. Williams' Syndrome Across Languages. Amsterdam: John Benjamins; 2004:221-244.

12. Joffe V, Varlokosta S. Language abilities in Williams syndrome: exploring comprehension, production and repetition skills. Adv Speech Lang Pathol. 2007;9(3):213-225.

13. Krause M, Penke M. Inflectional morphology in German Williams syndrome. Brain Cogn. 2002;48:410-412.

14. Levy Y. A longitudinal study of language development in children with Williams syndrome. J Child Lang. 2004;31(2):298-310.

15. Lukács A, Pléh C, Racsmány M. Language in Hungarian children with Williams syndrome. In: Bartke S, Siegmüller J, editors. Williams Syndrome Across Languages. Amsterdam: John Benjamins; 2004:187-221.

16. Lukács A, Racsmány M, Pléh C. Vocabulary and morphological patterns in Hungarian children with Williams syndrome: a preliminary report. Acta Linguistica. 2001;48:243-269.

17. Penke M, Krause M. Regular and irregular inflectional morphology in German Williams syndrome. In: Bartke S, Siegmüller J, editors. Williams Syndrome Across Languages. Amsterdam: John Benjamins; 2004:244-271.

18. Thomas MSC, Grant J, Barham Z, et al. Past tense formation in Williams syndrome. Language Cognitive Proc. 2001;16(2-3):143-176.

19. Capirci O, Sabbadini L, Volterra V. Language development in Williams' syndrome: a case study. Cognitive Neuropsychol. 1996;13(7):1017-1039.

20. Lukács A, Pléh C, Racsmány M. Spatial language in Williams syndrome: evidence for a special interaction? J Child Lang. 2007;34(2):311-343.

21. Volterra V, Capirci O, Pezzini G, Sabbadini L, Vicari S. Linguistic abilities in Italian children with Williams syndrome. Cortex. 1996; 32:663-677.

22. Losh M, Bellugi U, Reilly J, Anderson D. The integrity and independence of evaluation in narratives: evidence from children with Williams syndrome. Narrat Inq. 2001;10(2):1-26.

23. Reilly J, Losh M, Bellugi U, Wulfeck B. Frog, where are you?: Narratives in children with specific language impairment, early focal brain injury and Williams syndrome. Brain Lang. 2004;88:229-247. 
24. Bellugi U, Marks S, Bihrle A, Sabo H. Dissociation between language and cognitive functions in Williams syndrome. In: Bishop D, Mogford K, editors. Language Development in Exceptional Circumstances. London: Churchill Livingstone; 1988:171-189.

25. Bellugi U, Sabo H, Vaid J. Spatial deficit in children with Williams syndrome. In: Stiles-Davis J, Kritchevsky M, Bellugi U, editors. Spatial Cognition: Brain Bases and Development. Hillsdale, NJ: Lawrence Erlbaum; 1988:273-298.

26. Vicari S, Caselli MC, Gagliardi C, Tonucci F, Volterra V. Language acquisition in special populations: a comparison between Down and Williams syndromes. Neuropsychologia. 2002;40:2461-2470.

27. Volterra V, Caselli MC, Capirci O, Tonucci F, Vicari S. Early linguistic abilities of Italian children with Williams syndrome. Dev Neuropsychol. 2003;13(1-2):33-59.

28. Grant J, Valian V, Karmiloff-Smith A. A study of relative clauses in Williams syndrome. J Child Lang. 2002;29:430-416.

29. Bellugi U, Bihrle A, Jernigan T, Trauner D, Doherty S. Neuropsychological, neurological, and neuroanatomical profile of Williams' syndrome. Am J Med Genet Suppl. 1990;6:115-125.

30. Bromberg HS, Ullman M, Marcus G, Kelley KB, Levine K. A dissociation of lexical memory and grammar in Williams'syndrome: evidence from inflectional morphology. Poster presented at: The Sixth International Professional Conference of the Williams Syndrome Association; University of California, San Diego; 1994

31. Bromberg H, Ullman M, Marcus G, Kelly K, Coppola M. A dissociation of memory and grammar: evidence from Williams syndrome. Paper presented at: The 18th Annual Boston University Conference on Language Development; Boston; 1994.

32. Stevens T. Lexical constraints on language acquisition in Williams syndrome. [PhD Thesis]. MRC Cognitive Development Unit and University College London; 1996.

33. Stevens T, Karmiloff-Smith A. Word learning in a special population: do individuals with WS obey lexical constraints? J Child Lang. 1997;24:737-765.

34. Tyler L, Karmiloff-Smith A, Voice JK, et al. Do individuals with Williams syndrome have bizarre semantics? Evidence for lexical organization using an on-line task. Cortex. 1997;33:515-527.

35. Johnson S, Carey S. Knowledge enrichment and conceptual change in folk biology: evidence from Williams syndrome. Cogn Psychol. 1998;37:156-184.

36. Jarrold C, Hartley SJ, Phillips C, Baddeley AD. Word fluency in Williams syndrome: evidence for unusual semantic organization? Cogn Neuropsychiatry. 2000;5(4):293-319.

37. Temple CM, Almazan M, Sherwood S. Lexical skills in Williams syndrome: a cognitive neuropsychological analysis. J Neurolinguist. 2002;15:463-495.

38. Levy Y, Balchar T. Cognitive, lexical and morpho-syntactic profiles of Israeli children with Williams syndrome. Cortex. 2003;39:255-271.

39. Nazzi T, Karmiloff-Smith A. Early categorization abilities in young children with Williams syndrome. Neuroreport. 2002;13(10):1259-1262.

40. Sparrow SS, Balla D, Cicchetti D. Vineland Adaptive Behavior Scales. Circle Pines, MN: American Guidance Service; 1984.

41. Mervis CB, Klein-Tasman BP, Mastin ME. Adaptive behaviour of 4through 8-year children with Williams syndrome. Am J Ment Retard. 2001;106(4):82-93.

42. Laws G, Bishop VM. Pragmatic language impairment and social deficits in Williams syndrome: a comparison with Down's syndrome and specific language impairment. Int J Lang Commun Disord. 2004;39(1):4564.

43. Jones W, Bellugi U, Lai Z, et al. Hypersociability in Williams syndrome. J Cognitive Sci. 2000;12:30-47.

44. Jones W, Bellugi U, Lai Z. Hypersociability in Williams syndrome. In: Bellugi U, St George M, editors. Linking cognitive neuroscience and molecular genetics: new perspectives from Williams syndrome [Special Issue]. J Cognitive Neurosci. 2000;12(1):30-46.

45. Reilly J, Lacroix A, Poirier J, Bernicot J, Bellugi U, Klima E. Narratives in French and American children with Williams syndrome. Le Langage et l'Homme. 2005;40(2):111-126.
46. Reilly J, Bernicot J, Vicari S, Lacroix A, Bellugi U. Narratives in children with Williams syndrome: a cross-linguistic perspective. In: Ravid D, Batzeev Shyldkrot H, editors. Perspectives on Language and Language Development Essays in Honor of Ruth A. Berman. Dordrecht, Netherlands: Kluwer; 2004:303-312.

47. Stojanovik V, Perkins M, Howard S. Language and conversational abilities in Williams syndrome: how good is good? Int J Lang Commun Disord. 2001;36:234-239.

48. Stojanovik V. Social interaction deficits and conversational inadequacy in Williams syndrome. J Neurolinguist. 2006;19(2):157-173.

49. Lacroix A, Guidetti M, Rogé B, Reilly J. Recognition of emotional and nonemotional facial expressions: a comparison between Williams syndrome and autism. Res Dev Disabil. 2009;30:976-985.

50. Bellugi U, Wang P, Jernigan T. Williams syndrome: an unusual neuropsychological profile. In: Broman S, Grafman J, editors. Atypical Cognitive Deficits in Neurodevelopmental Disorders: Implications for Brain Function. Hillsdale, NJ: Lawrence Erlbaum; 1994:23-56.

51. Gagliardi C, Frigerio E, Burt DM, Cazzaniga I, Perrett DI, Borgatti R Facial expression recognition in Williams syndrome. Neuropsychologia. 2003;41:733-738.

52. Wang PP, Doherty S, Rourke SB, Bellugi U. Unique profile of visuoperceptual skills in a genetic syndrome. Brain Cogn. 1995;29(1): 54-65.

53. Plesa-Skewer D, Faja S, Verbalis A, Schofield C, Tager-Flusberg H. Perceiving facial and vocal expressions of emotion in Williams syndrome. Am J Ment Retard. 2006;111(1):15-26.

54. Skwerer DP, Verbalis A, Schofield C, Faja S, Tager-Flusberg H. Socialperceptual abilities in adolescents and adults with Williams syndrome. Cogn Neuropsychol. 2006;23(2):338-349.

55. Porter MA, Coltheart M, Langdon R. The neuropsychological basis of hypersociability in Williams and Down syndrome. Neuropsychologia. 2007;45:2839-2849.

56. Benton AL, Sivan AB, Hamsher KD, Varney NR, Spreen O. Contributions to Neuropsychological Assessment: A Clinical Manual. New York: Oxford University Press; 1983.

57. Deruelle C, Mancini J, Livet MO, Cassé-Perrot C, de Schonen S Configural and local processing of faces in children with Williams syndrome. Brain Cogn. 1999;41:276-298.

58. Tager-Flusberg H, Plesa-Skwerer D, Faja S, Joseph RM. People with Williams syndrome process faces holistically. Cognition. 2003;89(1):11-23.

59. Phillips KD. Emotion Regulation and Dysregulation in Children and Adolescents with Williams Syndrome (doctoral dissertation). Retrieved from ProQuest (UMI: 3332181); 2008.

60. American Psychiatric Association. Diagnostic and Statistical Manual of Mental Disorders. 5th ed. Arlington, VA: American Psychiatric Publishing; 2013.

61. Boucher J. The Autistic Spectrum: Characteristics, Causes and Practical Issues. London: Sage; 2009

62. Eigsti IM, Bennetto L, Dadlani M. Beyond pragmatics: morphosyntactic development in autism. J Autism Dev Disord. 2007;37:1007-1023.

63. Losh M, Adolphs R, Poe MD, et al. Neuropsychological profile of autism and the broad autism phenotype. Arch Gen Psychiatry. 2009;66(5):518-526.

64. Park S, Cho SC, Cho, IH, et al. Sex differences in children with autism spectrum disorders compared with their unaffected siblings and typically developing children. Res Autism Spect Disord. 2012;6: 861-870.

65. Tager-Flusberg H, Paul R, Lord CE. Language and communication in autism. In: Volkmar F, Paul R, Klin A, Cohen DJ, editors. Handbook of Autism and Pervasive Developmental Disorders. Vol 1. Diagnosis, Development, Neurobiology, and Behavior. New York: Wiley; 2005: 335-364.

66. Tager-Flusberg H, Calkins S, Nolin T, Baumberger T, Anderson M, Chadwick-Dias A. A longitudinal study of language acquisition in autistic and Down syndrome children. J Autism Dev Disord. 1990;20:1-21 
67. Szatmari P, Bryson S, Duku E, et al. Similar developmental trajectories in autism and Asperger syndrome: from early childhood to adolescence. J Child Psychol Psychiatry. 2009;50:1459-1467.

68. Naigles L, Kelty E, Jaffery R, Fein D. Abstractness and continuity in the syntactic development of young children with autism. Autism Res. 2011;4:422-437.

69. Bartolucci G, Pierce SJ, Streiner D. Cross-sectional studies of grammatical morphemes in autistic and mentally retarded children. JAutism Dev Disord. 1980;10:39-50.

70. Howlin P. The acquisition of grammatical morphemes in autistic children: a critique and replication of the findings of Bartolucci, Pierce, and Streiner, 1980. J Autism Dev Disord. 1984;14:127-136.

71. Kjelgaard M, Tager-Flusberg H. An investigation of language impairment in autism: implications for genetic subgroups. Lang Cogn Process. 2001;16:287-308.

72. Roberts JA, Rice ML, Tager-Flusberg H. Tense marking in children with autism. Appl Psycholinguist. 2004;25(3):429-448.

73. Perovic A, Modyanova N, Wexler K. Knowledge of c-command and A-movement in children and adolescents with autism and with Asperger syndrome. Paper presented at: GALA; 2007; Generative Approaches to Language Acquisition; Barcelona, Spain; 2007.

74. Tager-Flusberg H. On the nature of linguistic functioning in early infantile autism. J Autism Dev Disord. 1981;11:45-56.

75. Riches NG, Loucas T, Baird G, Charman T, Simonoff E. Sentence repetition in adolescents with specific language impairments and autism: an investigation of complex syntax. Int J Lang Commun Disord. 2010;45(1):47-60.

76. Fein D, Dunn MA, Allen DM, et al. Neuropsychological and language findings. In: Rapin I, editor. Preschool Children with Inadequate Communication: Developmental Language Disorder, Autism, Low IQ. London: MacKeith Press; 1996:123-154.

77. Swensen LD, Kelley E, Fein D, Naigles LR. Processes of language acquisition in children with autism: evidence from preferential looking. Child Dev. 2007;78:542-557.

78. Gastgeb HZ, Strauss MS, Minshew NJ. Do individuals with autism process categories differently? The effect of typicality and development. Child Dev. 2006;77:1717-1729.

79. Kelley E, Paul J, Fein D, Naigles L. Residual language deficits in optimal outcome children with a history of autism. J Autism Dev Disord. 2006;36:807-828.

80. Tek S, Jaffery G, Fein D, Naigles L. Do children with autism spectrum disorders show a shape bias in word learning? Autism Res. 2008; 1:208-222.

81. Baron-Cohen S, Ring H, Moriarty J, Shmitz P, Costa D, Ell P. Recognition of mental state terms: a clinical study of autism, and a functional neuroimaging study of normal adults. Br J Psychiatry. 1994;165:640-649.

82. Rutter M, Mawhood L, Howlin P. Language delay and social development. In: Fletcher P, Hall D, editors. Specific Speech and Language Disorders in Children: Correlates, Characteristics and Outcomes. London: Whurr; 1992:63-78.

83. Volden J. Conversational repair in speakers with autism spectrum disorders. Int J Lang Commun Disord. 2004;39:171-189.

84. Capps L, Kehres J, Sigman M. Conversational abilities among children with autism and children with developmental delays. Autism. 1998;2:325-344.

85. Capps L, Losh M, Thurber C. "The frog ate a bug and made his mouth sad": Narrative competence in children with autism. J Abnorm Child Psychol. 2000;28:193-204.

86. Baron-Cohen S, Tager-Flusberg H, Cohen DJ, editors. Understanding Other Minds: Perspectives from Autism. Oxford: Oxford University Press; 1993.

87. Dawson G, Meltzoff AN, Osterling J, Rinaldi J, Brown E. Children with autism fail to orient to naturally occurring social stimuli. J Autism Dev Disord. 1998;28:479-485.

88. Teunisse JP, De Gelder B. Do autistic children have a generalized face processing deficit? Int J Neurosci. 1994;77:1-10.
89. Sigman MD, Kasari C, Kwon JH, Yirmiya N. Responses to the negative emotions of others by autistic, mentally retarded, and normal children. Child Dev. 1992;63:796-807.

90. Dawson G, Carver L, Meltzoff A, Panagiotides H, McPartland J, Webb S. Neural correlates of face and object recognition in young children with autism spectrum disorder, developmental delay, and typical development. Child Dev. 2002;73:700-717.

91. Klin A, Sparrow SS, de Bildt A, Cicchetti DV, Cohen DJ, Volkmar FR. A normed study of face recognition in autism and related disorders. J Autism Dev Disord. 1999;29:499-508.

92. Narzisi A, Muratori F, Calderoni S, Fabbro F, Urgesi C. Neuropsychological profile in high-functioning autism spectrum disorders. J Autism Dev Disord. 2013;43:1895-1909.

93. Baron-Cohen S, Spitz A, Cross P. Do children with autism recognize surprise? A research note. Cogn Emot. 1993;7:507-516.

94. Capps L, Yirmiya N, Sigman M. Understanding of simple and complex emotions in non-retarded children with autism. J Child Psychol Psychiatry. 1992;33:1169-1182.

95. Yirmiya N, Sigman MD, Kasari C, Mundy P. Empathy and cognition in high-functioning children with autism. Child Dev. 1992;63:150-160.

96. Celani G, Battacchi MW, Arcidiacono L. The understanding of the emotional meaning of facial expressions in people with autism. J Autism Dev Disord. 1999;29:57-66.

97. Hobson RP, Ouston J, Lee A. What's in a face? The case of autism. Br J Psychol. 1988;79:441-453.

98. Loveland KA, Tunali-Kotoski B, Chen R, Brelsford KA, Ortegon J, Pearson DA. Intermodal perception of affect in persons with autism or Down syndrome. Dev Psychopathol. 1995;7:409-418.

99. Castelli F. Understanding emotions from standardized facial expressions in autism and normal development. Autism. 2005;9:428-449.

100. Lindner JL, Rosen LA. Decoding of emotion through facial expression, prosody, and verbal content in children and adolescents with Asperger's syndrome. J Autism Dev Disord. 2006;36:769-777.

101. Lacroix A, Guidetti M, Rogé B, Reilly J. Facial emotion recognition in 4- to 8-year-olds with autism spectrum disorder: a developmental trajectory approach. Res Autism Spect Disord. 2014;8(9): 1146-1154.

102. Philofsky A, Fidler DJ, Hepburn SL. Pragmatic language profiles of school-aged children with autism spectrum disorders and Williams syndrome. Am J Speech Lang Pathol. 2007;16:368-380.

103. Bishop DVM. The Children's Communication Checklist, Version 2 (CCC-2). London: Psychological Corporation; 2003.

104. Rose FE, Lincoln AJ, Lai Z, Ene M, Searcy YM, Bellugi U. Orientation and affective expression effects on face recognition in Williams syndrome and autism. J Autism Dev Disord. 2007;37:513-522.

105. Riby DM, Hancock PJB. Viewing it differently: social scene perception in Williams syndrome and autism. Neuropsychologia. 2008;46:2855-2860.

106. Johnson MH. The ontogeny of the social brain. In: Mayr U, Awh E, Keele SW, editors. Developing individuality in the human brain: A tribute to Michael Posner. Washington DC: APA press. 2005:125-140.

107. Annaz D, Karmiloff-Smith A, Johnson MH, Thomas MSC. A crosssyndrome study of the development of holistic face recognition in children with autism, Down syndrome and Williams syndrome. $J$ Exp Child Psychol. 2009;102:456-486.

108. Riby DM, Doherty-Sneddon G, Bruce V. The eyes or the mouth? Feature salience and unfamiliar face processing in Williams syndrome and autism. Q J Exp Psychol. 2009;62(1):189-203.

109. Riby DM, Doherty-Sneddon G, Bruce V. Exploring face perception in disorders of development: evidence from Williams syndrome and autism. J Neuropsychol. 2008;2:47-64.

110. Leyfer OT, Woodruff-Borden J, Klein-Tasman B, Fricke J, Mervis CB. Prevalence of psychiatric disorders in 4-16-year olds with Williams syndrome. Am J Med Genet B Neuropsychiatr Genet. 2006;114B:615-622. 
Pediatric Health, Medicine and Therapeutics

Dovepress

\section{Publish your work in this journal}

Pediatric Health, Medicine and Therapeutics is an international, peerreviewed, open access journal publishing original research, reports, editorials, reviews and commentaries. All aspects of health maintenance, preventative measures and disease treatment interventions are addressed within the journal. Practitioners from all disciplines are invited to submit their work as well as healthcare researchers and patient support groups. The manuscript management system is completely online and includes a very quick and fair peer-review system. Visit http://www.dovepress.com/ testimonials.php to read real quotes from published authors.

Submit your manuscript here: http://www.dovepress.com/pediatric-health-medicine-and-therapeutics-journal 